Article

\title{
Synergistic Effects of Trimethoprim with Flos Lonicerae on Antibacterial Activity and Dose-Effect Relationship in Vitro
}

\author{
Running Title: Synergistic Effects of Trimethoprim with Flos Lonicerae \\ Yizhi Cui, Qiuju Wang * and Xin Wang \\ College of Animal Science and Veterinary Medicine, Heilongjiang Bayi Agricultural University, \\ No. 2 Xinyang Road, New Development District, Daqing 163319, China; \\ cuiyizhe@byau.edu.cn (Y.C.); wn_2014@126.com (X.W.) \\ * Correspondence: wqj_9@126.com; Tel.: +86-182-4590-4030; Fax: 86-459-681-9198
}

\begin{abstract}
Observe the synergistic effect and dose-effect relationship of Trimethoprim (TMP) on bactericidal activity with Flos Lonicerae in vitro. Microamount chessboard dilution method was conducted to determine the minimal inhibitory concentration (MIC) of Trimethoprim, Flos Lonicerae, as well as the combination of Trimethoprim and Flos Lonicerae separately against Staphylococcus aureus, Escherichia coli in vitro and Salmonella. The pour plate count method was used to determine the combined bactericidal activity of Flos Lonicerae combined with Different concentrations TMP. The results showed that the MIC values of the combination of Flos Lonicerae with TMP was much less than the MIC values of the independent use of Flos Lonicerae or TMP, The FIC values of the combination of Flos Lonicerae with TMP were between 0.5 and 1 , there was additive effect between them. The bactericidal rates were fitted with least square method, the $95 \%$ confidence intervals of the optimal blending quantity about the combination of Flos Lonicerae with TMP on the test organisms were $231 \mu \mathrm{g} \cdot \mathrm{mL}^{-1}-249 \mu \mathrm{g} \cdot \mathrm{mL}^{-1}$, $237 \mu \mathrm{g} \cdot \mathrm{mL}^{-1}-259 \mu \mathrm{g} \cdot \mathrm{mL}^{-1}$, and $235-259 \mu \mathrm{g} \cdot \mathrm{mL}^{-1}$.
\end{abstract}

Keywords: Synergistic effect; Flos Lonicerae; Trimethoprim

\begin{abstract}
Introduction
Flos Lonicerae, also called Jinyinhua, is one of the widely used herbs prescribed in many Chinese formulas owing to its antibiotic property $[1,2]$. The main active ingredient is chlorogenic acid (Figure 1A). It has latent-heat-clearing, antipyretic, detoxicant and anti-inflammatory actions [3, 4]. It has been, therefore, prescribed to treat fever due to common cold, febrile disease, dysentery, carbuncles, and virulent swellings, and great progress has been made in the studies and clinical applications of Flos Lonicerae in the last couple of years [5].Trimethoprim is a folic acid antagonist, inhibits dihydrofolate reductase enzyme, which catalyses the conversion of dihydrofolate to tetrahydrofolic acid (Figure 1B), and this affects the biosynthesis of DNA [6]. This drug has been used clinically for the treatment of bacterial infections, including gastro and respiratory tract infections, in particular the common urinary tract infections [7].Although Flos Lonicerae and Trimethoprim have been extensively studied for many years, no investigation on the bactericidal activity of Trimethoprim-Flos Lonicerae has been reported so far. Herein the main purpose of the present study was to evaluate the synergistic effect and dose-effect relationship of Trimethoprim on bactericidal activity of Flos Lonicerae in vitro.
\end{abstract}




\section{Materials and Methods}

\section{Microorganisms}

Bacterial strains used in this research are Staphylococcus aureus ACTT 25923, Escherichia coli ATCC 35218 and Salmonella ATCC 50115 were obtained from the Institude of Microbiology Chinese Academy of Sciences. They were also employed as test organisms. Stock cultures were maintained at $4{ }^{\circ} \mathrm{C}$ on slopes of nutrient agar. The cultures were diluted to achieve optical densities corresponding to $1.0 \times 10^{7}$ colony forming units $(\mathrm{cfu} / \mathrm{ml})$ for bacterial strains.

Herb Extraction

Flos Lonicerae were purchased from Furuibang Medicine Limited Company (Daqing, China); the quality of the herb extract was controlled according to the requirements of Pharmacopoeia of the People's Republic of China. Trimethoprim was purchased from Kangruibao Medicine Limited Company (Taiyuan, China). The raw powder of Flos Lonicerae were dried at $50^{\circ} \mathrm{C}$ to constant weight. Approximately $10 \mathrm{~g}$ of pulverized sample (equivalently to $100 \mathrm{~g}$ crude drug) was added into an empty beaker with $100 \mathrm{ml}$ distilled water and $400 \mathrm{ml}$ dehydrated alcohol being poured respectively with constantly stir. The mixture was stored at $4{ }^{\circ} \mathrm{C}$ for $24 \mathrm{~h}$ followed by centrifugation at $4000 \mathrm{rpm}$ for $30 \mathrm{~min}$. The supernatant fraction was filtered with $0.45 \mu \mathrm{m}$ of filter membrane and pooled. The extracts were combined, concentrated and evaporated to dryness with rotary evaporator under reduced pressure. The ethanol was filtered and evaporated at $50^{\circ} \mathrm{C}$. The residue was dissolved with $50 \mathrm{ml}$ of distilled water into a $100 \mathrm{ml}$ beaker. This solution was regarded as a concentration of $200 \%$ ( $50 \mathrm{ml}$ of $\mathrm{HC}$ solution made from $100 \mathrm{~g}$ of raw material). After being autoclaved at $100^{\circ} \mathrm{C}$ for $20 \mathrm{~min}$, the stock solution was stored at $4^{\circ} \mathrm{C}$.

Antimicrobial susceptibility testing

Broth micro-dilution assay method and turbidimetric method was conducted to determine the antimicrobial susceptibility MIC of TMP and Flos Lonicerae against bacteria separately [6]. With sterile round-bottom 96-well plates, duplicate two-fold serial dilutions of extract (100 $\mu$ l per well) were prepared in the appropriate broth to produce a concentration range of 2000 to $15.6 \mathrm{mg} / \mathrm{ml}$ of extracts. A bacterial cell suspension (prepared in the appropriate broth) of $100 \mu 1$, corresponding to $1 \times 10^{6} \mathrm{cfu} / \mathrm{ml}$, was added in all wells except those in 3 columns which served as saline, extract and media sterility controls, respectively. Controls for bacterial growth without Flos Lonicerae extracts were also included on each plate. The final concentration of bacteria in the assay was $5 \times 10^{5} \mathrm{cfu} / \mathrm{ml}$. The final concentration of extracts ranged between 1000 to $7.8 \mathrm{mg} / \mathrm{ml}$. MIC of every extract was determined as the lowest concentration at which no bacterial growth was observed in the duplicate well after plates were then incubated at $37^{\circ} \mathrm{C}$ for $18 \mathrm{~h}$. Every test was performed in triplicate. Minimum bactericidal concentration (MBC) was determined by plating aliquots from those wells with no bacterial growth onto $\mathrm{MH}$ agar plates. $\mathrm{MBC}$ was defined as the lowest concentration of the extracts causing a $99.9 \%$ loss of viability with respect to the $\mathrm{cfu} / \mathrm{ml}$ inoculated.

Evaluation of synergy effect

Checkerboard assay was conducted to evaluate the synergy effect of Trimethoprim on bactericidal activity of Flos Lonicerae gainst Staphylococcus aureus, Escherichia coli and Salmonella separately in vitro. Checkerboard titration is one of the most frequently used techniques to access drug interactions. Test was performed utilizing 96 well microtiter plates. MICs were determined for every medicine by broth microdilution according to standards of the CLSI (Clinical Laboratory Standardization Institute). Each combination assay was performed at triplicates. Synergism by the checkerboard method was defined as an FIC index of $\leq 0.5$, additive effect was defined as an FIC index of $>0.5$ and $\leq 1$, Indifference effect was defined as an FIC index of $>1$ and $\leq 2$ and antagonism effect was defined as an FIC index of $>4$. Concentrations within the FIC panel were such that the MIC of each antibiotic was in the middle of the range of concentrations tested.

The FIC indices for all combinations were calculated using the formula below:

The FIC for a drug in a given well is derived by dividing the drug concentration in the given well by the control MIC of the test organism to that drug.

$F I C_{A}=M I C_{A}$ combination $/ M I C_{A}$ alone 
$F I C_{B}=M I C_{B}$ combination $/ M I C_{B}$ alone

The FIC index for a well is the sum of the FICs for each of the drugs present in the well:

$F I C_{\text {index }}=F I C_{A}+F I C_{B}$

Time-kill plot

Dose-effect relationship determinations were performed using two-fold dilution and plate count methods. The broth dilution assay was based on that recommended by the National Committee for Clinical Laboratory Standards. A series of twofold dilutions of each agent were prepared in medium broth. Trimethoprim was diluted to $640 \mu \mathrm{g} / \mathrm{ml}, 320 \mu \mathrm{g} / \mathrm{ml}, 160 \mu \mathrm{g} / \mathrm{ml}, 80 \mu \mathrm{g} / \mathrm{ml}$ and $40 \mu \mathrm{g} / \mathrm{ml}$. Flos Lonicerae was diluted to $2 \times$ MIC. The inoculum was prepared from a fresh broth culture and was finally $2.0 \times 10^{6} \mathrm{cfu} / \mathrm{ml}$ as confirmed by quantitative plate counts.

5 sterile labeled test tubes were used in this experiment, $1 \mathrm{ml}$ of TMP diluted solutions in 5 concentration and $1 \mathrm{ml}$ of $2 \times$ MIC Flos Lonicerae was added in all tubes separately, another 2 sterile tubes were used as extract and media sterility controls, respectively. The final concentration of bacteria in the assay was $1 \times 10^{5} \mathrm{cfu} / \mathrm{ml}$.

An aliquot of $0.1 \mathrm{ml}$ of inoculum cultured broth $\left(2.0 \times 10^{6} \mathrm{cfu} / \mathrm{ml}\right)$ was added to each tube. Then the final solutions were incubated at $37^{\circ} \mathrm{C}$ for $1,2,4$ and $8 \mathrm{~h}$, separately. Samples were plated onto LB agar plates to obtain viable colony counts and calculated bactericidal rate using the formula below:

Bactericidal rate $=($ control counts-drug control counts $) /$ control counts $\times 100 \%$

Experiments were performed in triplicates.

Statistical analysis

All data were expressed as the mean \pm SD. Comparison between groups was performed using ANOVA with post hoc correction for multiple comparisons using Prism software version 4.0c (Graphpad Software, Inc., San Diego, CA). Two-tailed Student $t$-test was used for other comparisons. The variance at the 0.05 level was considered as significance $(P<0.05)$.

\section{Results}

\section{Antimicrobial activity of the combination of Flos Lonicerae with TMP}

The antimicrobial activities of Flos Lonicerae and TMP against three indicator strains were shown in Table 1. The results showed that Flos Lonicerae and TMP had antibacterial activity against Staphylococcus aureus, Escherichia coli and Salmonella, the antibacterial activity against Escherichia coli at a much higher concentration $(250 \mathrm{mg} / \mathrm{ml}$ and $160 \mu \mathrm{g} / \mathrm{ml})$. In checkerboard assay, $62.5 \mathrm{mg} / \mathrm{ml}$ of Flos Lonicerae combine with $20 \mu \mathrm{g} / \mathrm{ml}$ of TMP (Fractional Inhibitory Concentration, FIC index $=0.75$ ) showed additive action against Staphylococcus aureus and Salmonella. The remaining combinations showed additive effect in the checkerboard assay.

Table 1: The antibacterial effect of the combination of Flos Lonicerae with TMP

\begin{tabular}{lcccccc}
\hline Bacteria Strain & \multicolumn{2}{c}{$\begin{array}{c}\text { MIC of TMP }(\mu \mathrm{g} / \mathrm{ml}) \\
\text { single }\end{array}$} & $\begin{array}{c}\text { MIC of Flos Lonicerae }(\mathrm{mg} / \mathrm{ml}) \\
\text { combination }\end{array}$ & $\begin{array}{c}\text { FIC } \\
\text { single }\end{array}$ & Rembination & index \\
\hline $\begin{array}{l}\text { Staphylococcus } \\
\text { aureus }\end{array}$ & 80 & 20 & 125 & 62.5 & 0.75 & Additive \\
$\begin{array}{l}\text { ACTT 25923 } \\
\begin{array}{l}\text { Escherichia coli } \\
\text { ATCC 35218 }\end{array}\end{array}$ & 160 & 40 & 250 & 125 & 0.75 & Additive \\
$\begin{array}{l}\text { Salmonella } \\
\text { ATCC 50115 }\end{array}$ & 80 & 20 & 125 & 62.5 & 0.75 & Additive \\
\hline
\end{tabular}

\section{Evaluation of synergy effect in vitro of antibacterial action over different time intervals}

Flos Lonicerae and different TMP diluted solutions were chosen for time-kill plot studies. Of these, Flos Lonicerae had an increased bactericidal efficacy on Staphylococcus aureus, Escherichia coli and Salmonella with time increased when they were administered in combination with TMP as shown in Figure 
2.

\section{Regression equation and fitting degree of sterilization rate}

Least square method was used to fit the bactericidal rate, the regression equation and fitting degree of bactericidal efficacy on Staphylococcus aureus, Escherichia coli and Salmonella at different time were concluded in Table 2. Optimal values of bactericidal efficacy of TMP in Staphylococcus aureus were $244 \mu \mathrm{g} \cdot \mathrm{mL}^{-1}, 248 \mu \mathrm{g} \cdot \mathrm{mL}^{-1}, 246 \mu \mathrm{g} \cdot \mathrm{mL}^{-1}$ and $224 \mu \mathrm{g} \cdot \mathrm{mL}^{-1}$ separately, and optimal values of TMP in $1 \mathrm{~h}, 2 \mathrm{~h}, 4 \mathrm{~h}$ and $8 \mathrm{~h}$ on Escherichia coli were $270 \mu \mathrm{g} \cdot \mathrm{mL}^{-1}, 241 \mu \mathrm{g} \cdot \mathrm{mL}^{-1}, 244 \mu \mathrm{g} \cdot \mathrm{mL}^{-1}$ and $238 \mu \mathrm{g} \cdot \mathrm{mL}^{-1}$ and optimal values of TMP in $1 \mathrm{~h}, 2 \mathrm{~h}, 4 \mathrm{~h}$ and $8 \mathrm{~h}$ on Salmonella were $230 \mu \mathrm{g} \cdot \mathrm{mL}^{-1}, 240 \mu \mathrm{g} \cdot \mathrm{mL}^{-1}, 251 \mu \mathrm{g} \cdot \mathrm{mL}^{-1}$ and $268 \mu \mathrm{g} \cdot \mathrm{mL}^{-1}$ respectively. The fiducial interval of $95 \%$ optimized additive concentration of TMP to enhance the bactericidal activity of Flos Lonicerae against Staphylococcus aureus and Escherichia coli were $231 \mu \mathrm{g} \cdot \mathrm{ml}^{-1}-249 \mu \mathrm{g} \cdot \mathrm{ml}^{-1}, 237 \mu \mathrm{g} \cdot \mathrm{ml}^{-1}-259 \mu \mathrm{g} \cdot \mathrm{ml}^{-1}$ and $235-259 \mu \mathrm{g} \cdot \mathrm{mL}^{-1}$ separately.

Table 2 Regression equation and fitting degree of bactericidal efficacy of on Flos Lonicerae and TMP

\begin{tabular}{|c|c|c|c|c|c|}
\hline \multirow[b]{2}{*}{ Organism } & \multirow[b]{2}{*}{ Time } & \multirow[b]{2}{*}{ Equation } & \multirow[b]{2}{*}{$\mathrm{R}^{2}$} & \multicolumn{2}{|c|}{$\operatorname{TMP}\left(\mu \mathrm{g} \cdot \mathrm{mL}^{-1}\right)$} \\
\hline & & & & optimal value & $\begin{array}{c}\text { confidence } \\
\text { interval }\end{array}$ \\
\hline Staphylococcus & $1 \mathrm{~h}$ & $y=-0.0005 x^{2}+0.2444 x+32.629$ & 0.9707 & 244 & \multirow{4}{*}{$231-249$} \\
\hline \multirow[t]{3}{*}{ aureus } & $2 \mathrm{~h}$ & $y=-0.0005 x^{2}+0.2477 x+48.486$ & 0.9813 & 248 & \\
\hline & $4 \mathrm{~h}$ & $y=-0.0004 x^{2}+0.1967 x+65.441$ & 0.9502 & 246 & \\
\hline & $8 \mathrm{~h}$ & $y=-0.0004 x^{2}+0.1793 x+77.064$ & 0.9885 & 224 & \\
\hline \multirow[t]{4}{*}{ Escherichia coli } & $1 \mathrm{~h}$ & $y=-0.0004 x 2+0.2158 x+32.301$ & 0.9595 & 270 & \multirow{4}{*}{$237-259$} \\
\hline & $2 \mathrm{~h}$ & $y=-0.0004 x 2+0.1926 x+49.327$ & 0.9736 & 241 & \\
\hline & $4 \mathrm{~h}$ & $y=-0.0004 x 2+0.1955 x+59.158$ & 0.9783 & 244 & \\
\hline & $8 \mathrm{~h}$ & $y=-0.0004 x 2+0.1900 x+69.856$ & 0.9798 & 238 & \\
\hline \multirow[t]{4}{*}{ Salmonella } & $1 \mathrm{~h}$ & $y=-0.0005 x 2+0.2295 x+32.999$ & 0.9634 & 230 & \multirow{4}{*}{$235-259$} \\
\hline & $2 \mathrm{~h}$ & $y-0.0005 x 2+0.2400 x+40.522$ & 0.9817 & 240 & \\
\hline & $4 \mathrm{~h}$ & $y=-0.0004 x 2+0.2009 x+51.288$ & 0.9717 & 251 & \\
\hline & $8 \mathrm{~h}$ & $y=-0.0003 x 2+0.1605 x+65.417$ & 0.9923 & 268 & \\
\hline
\end{tabular}

\section{Discussions}

In this study, the MICs of the traditional Chinese herbal medicines were detected. Although a considerable variety of plants showing an antimicrobial activity, variation of MIC still exists due to the bioassay methods employed in different studies, the sources and age of the plants, the solvent used for extraction, and strains. Results of our experiments suggested the substance responsible for the antimicrobial properties of Flos Lonicerae was produced within the area of the flower buds [8]. Furthermore, the strength of the inhibitor appears of increase over time. There are several possible explanations for the observed increase in the strength of the inhibitor. Plant material is biologically active and may undergo a variety of the biochemical changes in the postharvest period. Thus, the observed increase in inhibitor strength may be the result of an increased production of the inhibitor or the breakdown of some inhibition repressor. Alternatively, desiccation of stored material may play a part role in the observed increase of the strength of the inhibitor. Flos Lonicerae fruits loose water rapidly after harvest and continue to decline in water content during storage. Herein, the relative amount of the inhibitor may remain constant, but its specific activity may increase with a concomitant reduction in the water content of the flower buds.

When testing the activity of antimicrobial compounds in vitro it is important to use standardized conditions that allow meaningful assessments. In this way, the activity of a given compound against different microorganisms or of different compounds against the same microorganism can be compared. For this reason, there are accepted guidelines to measure the in vitro activity of classical antibiotics, since guidelines for the microamount chessboard dilution method [9]. The susceptibility of Staphylococcus aureus, Escherichia coli and Salmonella to water extracts of Flos Lonicerae was examined and screened in this study with broth dilution diffusion, a quantitative assay method, which is less time-consuming and less 
labor-intensive than agar dilution method, and cheaper than E test [10]. Both selected herbal medicines are the commonly used traditional Chinese herbal medicines prescribed by physicians of traditional Chinese medicine [11-13] Flos Lonicerae is even recommended as a dietetic therapy for health preserving. More importantly, both of the selected herbal medicines have a same standard from the Furuibang Corporation, which provided the herbs in this study.

The susceptibilities of two isolated Staphylococcus aureus, Escherichia coli and Salmonella strains to Flos Lonicerae were tested in this study. Previous studies as well have described the effect of Flos Lonicerae against Staphylococcus aureus [14] and Escherichia coli. The results of this study demonstrated the inhibitory effect of Flos Lonicerae-TMP against Staphylococcus aureus and Escherichia coli for the first time. In this study, the inhibitory effect of Flos Lonicerae-TMP had a stronger anti-Staphylococcus aureus, anti-Escherichia coli and anti-Salmonella activity than alone, indicating that the compound can be used as useful sources for the synthesis of novel drugs against Staphylococcus aureus, Escherichia coli and Salmonella strains.

Traditional Chinese medicines have a long history, due to their effectiveness and relatively low toxicity, and herbal medicines have drawn more and more attention during the last decade [15, 16] Chemical compositions of Flos Lonicerae has been extensively studied. In our study, water extracts from the medicinal plants demonstrated a strong anti-Staphylococcus aureus and anti-Salmonella strains activity, and a wide range of phytochemistry materials from medicinal plants could reduce the inflammatory response, indicating that the two herbal drugs can be used as anti-inflammatory or antibacterial agents. The strong in vitro anti-Staphylococcus aureus and anti- Salmonella activity of these water extracts does not necessarily imply that they have a strong in vivo anti-Staphylococcus aureus and anti-Salmonella activity. On the other hand, some parts of the two plants may be more potent in vivo due to metabolic transformation of their components into highly active intermediates. Studies of effectiveness of Flos Lonicerae on diseases due to Staphylococcus aureus and Salmonella in the animal model could help resolve this question.

It is exciting that Flos Lonicerae-TMP with a strong anti-Staphylococcus aureus, anti-Escherichia coli and anti-Salmonella activity may provide the potential sources of new drugs, thus reducing the morbidity of diseases and improving the eradication rate and relapse of Staphylococcus aureus, Escherichia coli and Salmonella infection.

\section{Figure Legends}

A<smiles>O=C(/C=C/c1ccc(O)c(O)c1)O[C@H]1C[C@@](O)(C(=O)O)C[C@H](O)[C@H]1O</smiles>

Chlorogenic acid

【Formula】 $\mathrm{C} 16 \mathrm{H} 18 \mathrm{O} 9$

【Molecular Weight】 354.31
B<smiles>COc1cc(Cc2cnc(N)nc2N)cc(OC)c1OC</smiles>

Trimethoprim

【Formula】 $\mathrm{C} 14 \mathrm{H} 18 \mathrm{~N} 4 \mathrm{O} 3$

【Molecular Weight】 290.32

Figure 1. Structures of Chlorogenic acid and Trimethoprim. 

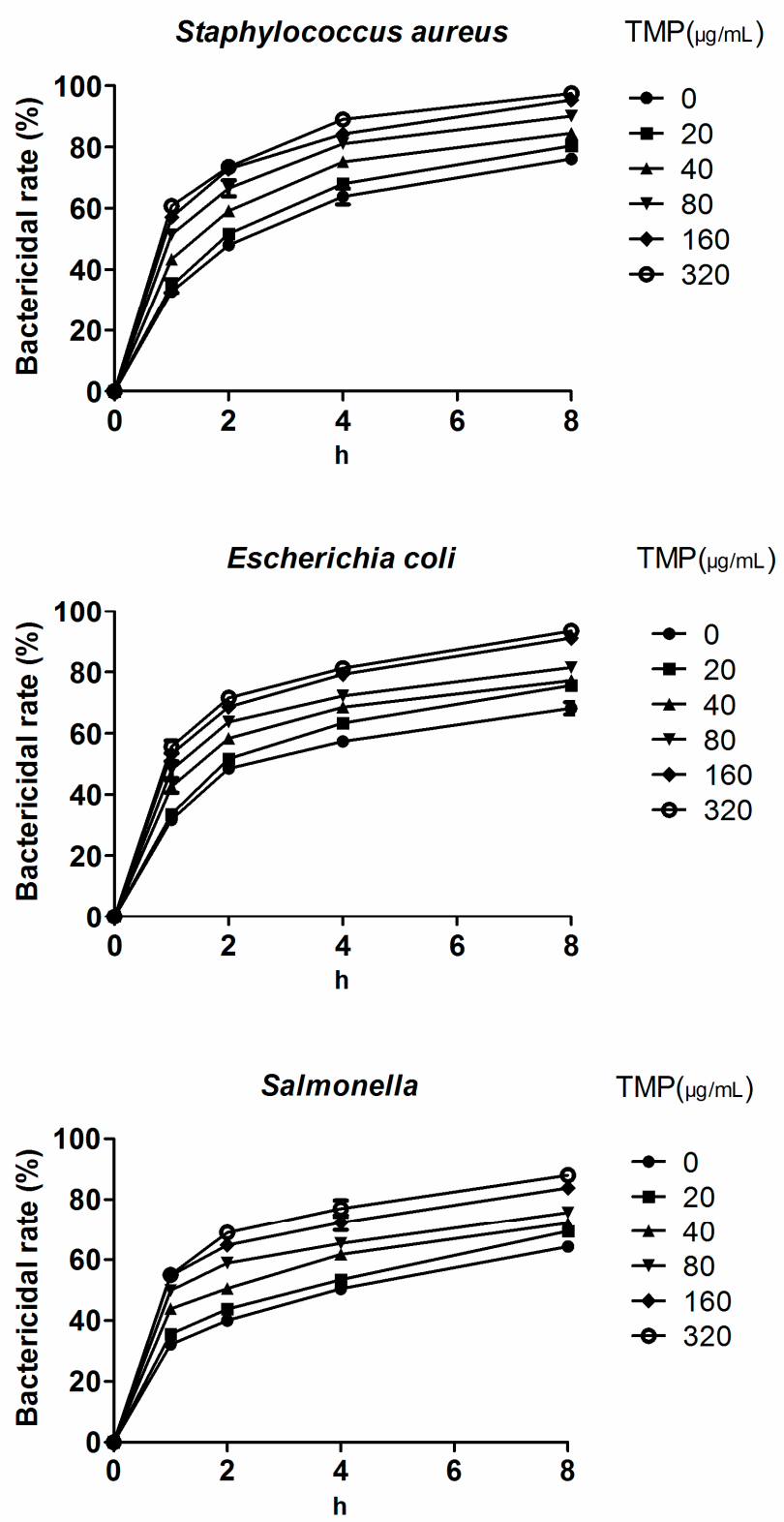

Figure 2. Bactericidal rate of TMP combined with Flos Lonicerae. Bactericidal rate of TMP combined with Flos Lonicerae on Staphylococcus aureus, Escherichia coli and Salmonella by being cultured for 1 hour, 2 hours, 4 hours and 8 hours. All values represent the mean $\pm \mathrm{SD}(\mathrm{n}=3)$ against the control levels. Mean differences are significant from control group at $P<0.05\left(^{*}\right)$.

Acknowledgments: This work was supported by The Natural Science Foundation of Heilongjiang Province (No. C201444， C2015040) and Heilongjiang Bayi Agricultural University Project Funding (No. XZR2014-05)

Declarations: The authors declare that they have no competing interests.

\section{References}

1. Choi, C. W.; Jung, H. A.; Kang, S. S.; Choi, J. S., Antioxidant constituents and a new triterpenoid glycoside from Flos Lonicerae. Archives of pharmacal research 2007, 30, (1), 1-7.

2. Liu, J. H.; Ho, S. C.; Lai, T. H.; Liu, T. H.; Chi, P. Y.; Wu, R. Y., Protective effects of Chinese herbs on D-galactose-induced oxidative damage. Methods and findings in experimental and 
clinical pharmacology 2003, 25, (6), 447-52.

3. Chen, J.; Song, Y.; Li, P., Capillary high-performance liquid chromatography with mass spectrometry for simultaneous determination of major flavonoids, iridoid glucosides and saponins in Flos Lonicerae. Journal of chromatography. A 2007, 1157, (1-2), 217-26.

4. Wu, L., Effect of chlorogenic acid on antioxidant activity of Flos Lonicerae extracts. Journal of Zhejiang University. Science. B 2007, 8, (9), 673-9.

5. Ku, S. K.; Seo, B. I.; Park, J. H.; Park, G. Y.; Seo, Y. B.; Kim, J. S.; Lee, H. S.; Roh, S. S., Effect of Lonicerae Flos extracts on reflux esophagitis with antioxidant activity. World journal of gastroenterology : WJG 2009, 15, (38), 4799-805.

6. Mann, C. M.; Markham, J. L., A new method for determining the minimum inhibitory concentration of essential oils. Journal of applied microbiology 1998, 84, (4), 538-44.

7. Abou-Eisha, A., Evaluation of cytogenetic and DNA damage induced by the antibacterial drug, trimethoprim. Toxicology in vitro : an international journal published in association with BIBRA 2006, 20, (5), 601-7.

8. Qian, Z. M.; Wen, X. D.; Li, H. J.; Liu, Y.; Qin, S. J.; Li, P., Analysis of interaction property of bioactive components in Flos Lonicerae Japonicae with protein by microdialysis coupled with HPLC-DAD-MS. Biological \& pharmaceutical bulletin 2008, 31, (1), 126-30.

9. Fanaki, N. H.; El-Nakeeb, M. A., Antibacterial activity of benzydamine and antibiotic-benzydamine combinations against multifold resistant clinical isolates. Arzneimittel-Forschung 1996, 46, (3), 320-3.

10. Marks, M. I.; Kazemi, M.; MacKay, E., In vitro sensitivity of Salmonella to ten antimicrobial agents including sulfamethoxazole and trimethoprim, alone and in combination. Antimicrobial agents and chemotherapy 1973, 4, (5), 555-9.

11. Ni, L. J.; Zhang, L. G.; Hou, J.; Shi, W. Z.; Guo, M. L., A strategy for evaluating antipyretic efficacy of Chinese herbal medicines based on UV spectra fingerprints. Journal of ethnopharmacology 2009, 124, (1), 79-86.

12. Wong, R. W.; Hagg, U.; Samaranayake, L.; Yuen, M. K.; Seneviratne, C. J.; Kao, R., Antimicrobial activity of Chinese medicine herbs against common bacteria in oral biofilm. A pilot study. International journal of oral and maxillofacial surgery 2010, 39, (6), 599-605.

13. $\mathrm{Xu}, \mathrm{H} . ; \mathrm{Xu}, \mathrm{H}$. E., Analysis of trace elements in Chinese therapeutic foods and herbs. The American journal of Chinese medicine 2009, 37, (4), 625-38.

14. Hon, K. L.; Chan, B. C.; Leung, P. C., Chinese herbal medicine research in eczema treatment. Chinese medicine 2011, 6, 17.

15. Sarris, J.; Kean, J.; Schweitzer, I.; Lake, J., Complementary medicines (herbal and nutritional products) in the treatment of Attention Deficit Hyperactivity Disorder (ADHD): a systematic review of the evidence. Complementary therapies in medicine 2011, 19, (4), 216-27.

16. McCulloch, M.; Broffman, M.; van der Laan, M.; Hubbard, A.; Kushi, L.; Kramer, A.; Gao, J.; Colford, J. M., Jr., Lung cancer survival with herbal medicine and vitamins in a whole-systems approach: ten-year follow-up data analyzed with marginal structural models and propensity score methods. Integrative cancer therapies 2011, 10, (3), 260-79.

(C) 2016 by the authors; licensee Preprints, Basel, Switzerland. This article is an open access article distributed under the terms and conditions of the Creative Commons by Attribution (CC-BY) license (http://creativecommons.org/licenses/by/4.0/). 